\title{
Open descending thoracic or thoracoabdominal aortic approaches for complications of endovascular aortic procedures: 19-year experience
}

Konstantinos Spiliotopoulos, MD, PhD, FETCS, ${ }^{\mathrm{a}, \mathrm{b}, \mathrm{c}}$ Ourania Preventza, MD, ${ }^{\mathrm{a}, \mathrm{b}, \mathrm{c}, \mathrm{d}}$ Susan Y. Green, MPH, ${ }^{\mathrm{a}}$ Matt D. Price, MS, RHIA, ${ }^{\mathrm{a}}$ Hiruni S. Amarasekara, MS, ${ }^{\mathrm{a}}$ Brittany M. Davis, BS, ${ }^{\mathrm{a}}$ Kim I. de la Cruz, MD, ${ }^{a, b, c, d}$ Scott A. LeMaire, MD, ${ }^{a, b, c, d}$ and Joseph S. Coselli, MD ${ }^{\mathrm{a}, \mathrm{b}, \mathrm{c}, \mathrm{d}}$

\section{ABSTRACT}

Objectives: Endovascular aortic repair is increasingly being used to treat aneurysms, dissections, and traumatic injuries, despite its unknown long-term durability. We describe our 19-year experience with open descending thoracic and thoracoabdominal aortic repair after endovascular aortic repair.

Methods: Between 1996 and 2015, 67 patients were treated with open distal arch, descending thoracic, or thoracoabdominal aortic repair, or extra-anatomic bypass repair with aortic extirpation for complications after endovascular repair of the thoracic $(\mathrm{n}=45,67 \%)$ or abdominal $(\mathrm{n}=22,33 \%)$ aorta. The median interval between procedures was 18.0 months (interquartile range, 3.9-44.9). Indications for open repair included expanding aneurysm $(\mathrm{n}=56)$, infection $(\mathrm{n}=11)$, fistula $(\mathrm{n}=8)$, aneurysm rupture $(\mathrm{n}=5)$, pseudoaneurysm $(\mathrm{n}=2)$, and restenosis $(\mathrm{n}=1)$. Open repair involved partial $(\mathrm{n}=9,13 \%)$ or complete $(\mathrm{n}=56,84 \%)$ device removal or device salvage $(\mathrm{n}=2,3 \%)$ through a thoracoabdominal $(\mathrm{n}=58,87 \%)$ or thoracotomy $(\mathrm{n}=9,13 \%)$ incision. Eight patients $(12 \%)$ underwent emergency procedures.

Results: There were 3 early (operative) deaths ( 2 with preoperative device infection) and 19 late deaths during a median follow-up of 35.8 months (interquartile range, 16.8-52.8 months). Overall 1 - and 5-year survivals were $85 \% \pm 4 \%$ and $60 \% \pm 8 \%$, respectively. Four patients had open repair failures necessitating reoperation; 2 patients had preoperative infection, and both died ( 1 early and 1 late).

Conclusions: Open repair for complications after endovascular procedures is not uncommon. Experienced centers can yield acceptable outcomes, especially in patients without infection. Close surveillance is mandatory after endovascular aortic repair. (J Thorac Cardiovasc Surg 2018;155:10-8)

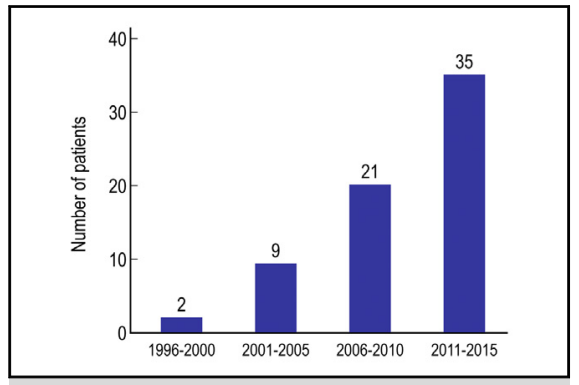

Increase in the number of open repairs of previous EAR complications from 1996 to 2015.

\section{Central Message}

Open aortic repair after EAR is a challenging procedure, but acceptable results can be achieved when infection is absent.

\section{Perspective}

Complications after EAR can be severe enough to require open repair. We present our experience with 67 patients, including operative strategy, postoperative management, and outcomes for these especially challenging cases.

See Editorial Commentary page 19.
The rate of endovascular aortic repair (EAR), both thoracic endovascular aortic repair (TEVAR) and endovascular abdominal aortic repair (EVAR), has increased dramatically

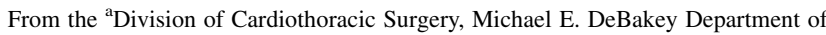
Surgery, and ${ }^{\mathrm{d}}$ Cardiovascular Research Institute, Baylor College of Medicine; ${ }^{\mathrm{b}}$ Department of Cardiovascular Surgery, Texas Heart Institute; and ${ }^{\mathrm{c}} \mathrm{CHI}$ St Luke's Health-Baylor St Luke's Medical Center, Houston, Tex.

Read at the 2016 Aortic Symposium of The American Association for Thoracic Surgery, New York, New York, May 12-13, 2016.

Received for publication June 9, 2016; revisions received July 20, 2017; accepted for publication Aug 11, 2017; available ahead of print Sept 19, 2017.

Address for reprints: Scott A. LeMaire, MD, One Baylor Plaza, BCM 390, Houston, TX 77030 (E-mail: slemaire@bcm.edu).

$0022-5223 / \$ 36.00$

Copyright (c) 2017 by The American Association for Thoracic Surgery

http://dx.doi.org/10.1016/j.jtcvs.2017.08.023 over the last 2 decades. ${ }^{1,2}$ Despite its unknown long-term durability, EAR has become the treatment of choice in many centers for aortic aneurysm, dissection, traumatic injury, aortic coarctation, and other related conditions.

Considering the increasing number of EAR cases performed every year, it is not surprising that the rate of complications associated with these repairs has increased

- Scanning this $\mathrm{QR}$ code will take you to a supplemental video for the article. 


\section{Abbreviations and Acronyms \\ AAA $=$ abdominal aortic aneurysm \\ CTD = connective tissue disorder \\ EAR = endovascular aortic repair \\ EVAR = endovascular abdominal aortic repair \\ IQR = interquartile range \\ MOF = multiple organ failure \\ TEVAR $=$ thoracic endovascular aortic repair}

accordingly. These complications include endoleak, expanding aortic aneurysm despite endovascular aneurysm exclusion, expanding false lumen after endovascular repair of acute or chronic aortic dissection, fistula formation, stent-graft infection, fracture, and migration. Although many of the complications can be managed endovascularly in experienced centers, ${ }^{3-9}$ open surgical repair is warranted in a small fraction of cases.

Over the last 2 decades, our group has gained significant experience with open surgical repair after previous EAR, treating both complications and disease progression after EAR. However, in the present study, we focused on analyzing outcomes of open transthoracic surgical repair specifically in patients who presented with complications after previous EAR or had continuing complications after EAR that necessitated further repair.

\section{PATIENTS AND METHODS}

\section{Study Enrollment and Patient Characteristics}

In 2006, the institutional review board of Baylor College of Medicine approved our clinical research protocol for prospective collection and analysis of clinical data. Informed consent was obtained when possible from all patients enrolled after protocol approval. We obtained a waiver of consent for patients who were unable to consent because of illness and who had no family members to provide consent for them. For patients who underwent surgery before 2006, we obtained a waiver of consent from the institutional review board and collected data retrospectively from medical records.

Between November 1996 and September 2015, 123 patients with previous EAR (both TEVAR and EVAR) underwent open or endovascular reintervention for disease progression, EAR-related complications, or continued complications after EAR that necessitated further repair. The majority of patients $(n=84,68 \%)$ were referred from an outside center.

Of the 123 patients, $87(71 \%)$ underwent an open repair. From this group, we excluded 8 patients who underwent replacement of the infrarenal aorta only without involvement of the thoracic component, 2 patients with involvement of the ascending aorta only, and 1 patient whose repair was performed through a clavicular incision only. Finally, we excluded 9 patients with an intact and fully salvaged EAR who required open repair solely for disease progression in a contiguous segment of their aorta.

Thus, this study focused on 67 consecutive patients (Figure 1) who had new or continued complications after EAR and who were treated with open distal aortic repair in which a lateral thoracotomy or thoracoabdominal incision was used to repair an aortic segment containing 1 or more endografts (Table 1). Twenty-nine $(43 \%)$ of these patients had a prior open aortic repair, and $22(33 \%)$ had a genetically triggered aortic disorder.

The previous EAR was performed at an outside institution in most patients $(56 / 67,84 \%)$; for these patients, basic information regarding

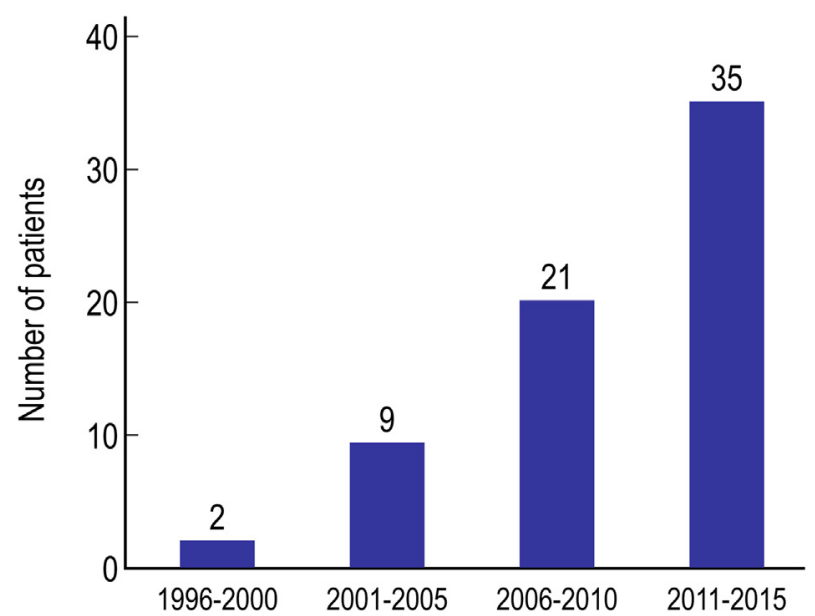

FIGURE 1. Number of patients with complications after EAR who were treated with open distal aortic repair via a lateral thoracotomy or thoracoabdominal incision between November 1996 and November 2015 $(\mathrm{n}=67)$. The previous EAR was performed at an outside institution in the majority of patients $(n=56,84 \%)$.

EAR was retrospectively abstracted from outside medical records (Table 1). The type of EAR performed was thoracic in 45 patients (TEVAR, $67 \%$ ) and abdominal in 22 patients (EVAR, 33\%); 1 patient underwent both TEVAR and EVAR and was assigned to the TEVAR group because TEVAR was the more extensive repair. At the time of open aortic repair, 48 patients $(72 \%)$ had a single previous EAR procedure, 18 patients $(27 \%)$ had 2 such procedures, and 1 patient $(1 \%)$ had 3 previous EARs. Most commonly, endovascular reintervention was performed to treat endoleak. The median interval between initial EAR and open aortic repair was 18.0 months (interquartile range [IQR], 3.9-44.9 months) and ranged from 2 days to approximately 19 years. Six patients $(9 \%)$ underwent open repair within 1 month of the previous EAR, 8 patients $(12 \%)$ underwent open repair between 1 and 3 months, 6 patients $(9 \%)$ underwent open repair between 3 and 6 months, 9 patients $(13 \%)$ underwent open repair between 6 and 12 months, and 38 patients (57\%) underwent open repair more than 12 months after EAR.

Indications for the primary EAR were abdominal aortic aneurysm (AAA) $(\mathrm{n}=21,31 \%)$, descending thoracic aortic aneurysm $(\mathrm{n}=8$, $12 \%)$, distal arch aneurysm $(\mathrm{n}=1,1 \%)$, acute or subacute aortic dissection $(\mathrm{n}=11,16 \%)$, chronic aortic dissection $(\mathrm{n}=18,27 \%)$, pseudoaneurysm $(n=4,6 \%)$, fistula $(n=2,3 \%)$, ruptured mycotic aneurysm $(\mathrm{n}=1,1 \%)$, and long coarctation/middle chest syndrome $(\mathrm{n}=1,1 \%)$. Of the 6 cases of pseudoaneurysm or fistula, 5 of them resulted from complications of prior open distal aortic repair. Although stent-grafts were used in the majority of EARs, bare-metal stents were used in 4 cases.

At the time of the index open transthoracic repair, infection was present in 11 patients $(16 \%)$, including $8(12 \%)$ with fistula. Five patients $(7 \%)$ had rupture. Regarding aortic dissection, there were $4(6 \%)$ acute or subacute cases and $32(48 \%)$ chronic cases. Of these, there were 3 cases in which distal aortic dissection occurred after EAR, including 1 case of retrograde DeBakey type I aortic dissection that occurred days after EAR and that required emergency proximal aortic repair, which was followed by the index distal aortic repair 3 months later. Two patients had pseudoaneurysm as a complication of prior open repair that was not resolved by EAR, and 2 additional patients with prior open repair developed a patch aneurysm after EAR. One patient with middle aortic syndrome that was initially treated with bare-metal stents had restenosis that necessitated open repair. In most cases $(n=56,82 \%)$, open repair was necessitated by expanding aneurysm, and endoleak was documented in $30(45 \%)$. 
TABLE 1. Preoperative characteristics of patients at time of open repair, stratified by previous endovascular procedure

\begin{tabular}{|c|c|c|c|}
\hline Variable & All $(n=67)$ & TEVAR $(n=45)^{*}$ & $\operatorname{EVAR}(\mathbf{n}=22)$ \\
\hline Age (y) & $61[49-71]$ & $54[41-66]$ & $70[65-74]$ \\
\hline Male & $46(69)$ & $27(60)$ & $19(86)$ \\
\hline Genetically triggered disorder & $22(33)$ & $22(49)$ & 0 \\
\hline Connective tissue disorder & $17(25)$ & $17(38)$ & 0 \\
\hline Marfan syndrome & $14(21)$ & $14(31)$ & 0 \\
\hline Loeys-Dietz syndrome & $2(3)$ & $2(4)$ & 0 \\
\hline Aortic aneurysm without dissection & $28(42)$ & $11(24)$ & $17(77)$ \\
\hline Aortic dissection & $36(54)$ & $33(73)$ & $3(14)$ \\
\hline Acute or subacute dissection & $4(6)$ & $3(7)$ & $1(5)$ \\
\hline Chronic dissection & $32(48)$ & $30(67)$ & $2(9)$ \\
\hline DeBakey type I & $14(21)$ & $13(29)$ & $1(5)$ \\
\hline DeBakey type IIIa & $3(4)$ & $3(7)$ & 0 \\
\hline DeBakey type IIIb & $20(30)$ & $18(40)$ & $2(9)$ \\
\hline$>1$ distal dissection & $1(1)$ & $1(2)$ & 0 \\
\hline Preoperative serum creatinine, $\mathrm{mg} / \mathrm{dL} \ddagger$ & $\begin{array}{l}1.0[0.8-1.3] \\
\quad(\mathrm{n}=64)\end{array}$ & $\begin{array}{c}1.0[0.8-1.2] \\
(n=43)\end{array}$ & $\begin{array}{c}1.3[1.0-1.5] \\
(\mathrm{n}=21)\end{array}$ \\
\hline Hypertension & $58(87)$ & $39(87)$ & $19(86)$ \\
\hline Hyperlipidemia & $34(51)$ & $20(44)$ & $14(64)$ \\
\hline Diabetes & $10(15)$ & $4(9)$ & $6(27)$ \\
\hline Current tobacco use & $8(12)$ & $3(7)$ & $5(23)$ \\
\hline Prior open aortic repair $\S$ & $29(43)$ & $25(56)$ & $4(18)$ \\
\hline Rupture & $5(7)$ & $2(4)$ & $3(14)$ \\
\hline \multicolumn{4}{|l|}{ Characteristics at time of open repair } \\
\hline Restenosis of long coarctation & $1(1)$ & $1(2)$ & 0 \\
\hline Infection & $11(16)$ & $9(20)$ & $2(9)$ \\
\hline With fistula & $8(12)$ & $7(16)$ & $1(5)$ \\
\hline Endoleak & $30(45)$ & $19(42)$ & $11(50)$ \\
\hline Patch aneurysm (after open aortic repair) & $2(3)$ & $2(4)$ & 0 \\
\hline Pseudoaneurysm (after open aortic repair) & $2(3)$ & $2(4)$ & 0 \\
\hline \multicolumn{4}{|l|}{ Details regarding previous EAR } \\
\hline Performed at outside facility & $56(84)$ & $36(80)$ & $20(91)$ \\
\hline Performed at our facility & $11(16)$ & $9(20)$ & $2(9)$ \\
\hline Acute dissection at time of EAR & $9(13)$ & $9(20)$ & 0 \\
\hline Subacute dissection at time of EAR & $2(3)$ & $2(4)$ & 0 \\
\hline Chronic dissection at time of EAR & $22(33)$ & $21(47)$ & $1(5)$ \\
\hline EAR to treat complication of open repair & $5(7)$ & $5(11)$ & 0 \\
\hline $\begin{array}{l}\text { Interval between endovascular procedure and } \\
\text { index open procedure, mo }\end{array}$ & $18.0[3.9-44.9]$ & $11.2[1.8-32.6]$ & $29.2[17.4-58.3]$ \\
\hline
\end{tabular}

$\overline{T E V A R}$, Thoracic endovascular aortic repair; EVAR, endovascular abdominal aortic repair; EAR, endovascular aortic repair. *Includes 3 bare-metal stents. $\dagger$ Includes 1 bare-metal stent. †Data for 3 patients are missing. $§$ At any portion of the aorta (proximal or distal). Data presented as n (\%) or median [IQR].

\section{Definitions of Variables and Follow-up}

We used our previously reported standard definitions for preoperative, operative, and outcomes variables. ${ }^{10,11}$ Operative (or early) death was defined as any death taking place within 30 days of the operation or before final discharge from our or any hospital or long-term acute care facility. Late death was defined as death that occurred after the early postoperative period (ie, any death that occurred $>30$ days after the index repair and after final discharge from the index hospitalization). A composite end point, adverse event, comprised operative death or persistent (present at hospital discharge) stroke, paraplegia, paraparesis, or renal failure necessitating dialysis. ${ }^{12}$ Infection was broadly defined and included cases of mycotic aneurysm, fistula, graft infection related to complications of prior open repair, and endograft infection. Length of stay for early survivors was the number of days between the open repair and final discharge, as defined earlier. Distal aortic reintervention was defined as additional open or endovascular repair of the descending thoracic, thoracoabdominal, or abdominal aorta because of repair failure or progression of aortic disease.

Finally, our best effort was made to collect and review reports and follow-up imaging studies of the initial EAR and any subsequent aortic repairs in our study group. Clinical follow-up data were acquired through clinic visits, telephone interviews, or written correspondence; these data were collected for all but 5 patients $(7 \%)$ who were lost to follow-up at hospital discharge. The Social Security Death Index was reviewed and 
internet obituary searches were performed to identify whether the 5 patients who were lost to clinical follow-up had died. Of the 5 patients, 4 were confirmed dead by the Social Security Death Index database, and 1 patient was presumed alive.

\section{Surgical Techniques}

Our surgical approach for managing complications after a previous EAR procedure was based on our established techniques of exposure and multimodal adjunctive protocols for organ protection as described previously for thoracic and thoracoabdominal aortic cases. ${ }^{11,13-15}$ In brief, this approach included moderate systemic heparinization $(1.0 \mathrm{mg} / \mathrm{kg})$, mild permissive hypothermia $\left(32^{\circ} \mathrm{C}-34^{\circ} \mathrm{C}\right)$, left heart bypass, cerebrospinal fluid drainage, and selective visceral perfusion in extensive repairs (extent I and II thoracoabdominal aortic aneurysm repairs), and cold renal perfusion when the renal arteries were accessible. Repairs were performed through a thoracoabdominal $(\mathrm{n}=58$, $87 \%$ ) or left posterolateral thoracotomy $(n=9,13 \%)$ incision (Table 2). Four patients $(6 \%)$ had completion of a prior elephant trunk procedure, and 1 patient $(1 \%)$ had a reverse elephant trunk procedure. Urgent or emergency procedures were performed in 28 patients $(42 \%)$.

We performed full salvage $(n=2,3 \%)$, partial extraction $(n=9,13 \%)$, or complete extraction $(n=56,84 \%)$ of the previously implanted aortic stent-graft. The decision whether to perform a complete extraction, partial extraction, or full salvage of the previously deployed endoprosthesis was usually made intraoperatively; the stent-graft was fully extracted whenever infection was identified and complete device removal was deemed safe. Although we do not routinely use hypothermic circulatory arrest, this approach was used in 6 repairs in which the proximal aorta could not be safely clamped because the stent-graft had been deployed well into the aortic $\operatorname{arch}(n=4)$ or because of prohibitively large aneurysm size $(n=2)$.

The 2 full-salvage cases involved complications of previous EAR. One case was an expanding AAA due to type II endoleak after EVAR; we performed a thoracoabdominal incision, opened the thrombosed aortic sac of the previously endovascularly excluded AAA, and over-sewed the 2 lumbar arteries and the inferior mesenteric artery (which we identified as the source of the endoleak), finally closing the sac over the fully salvaged abdominal stent-graft. The second full-salvage case involved an elderly patient in whom an aortobronchial fistula developed 6 years after hybrid EAR to treat a distal arch aneurysm; in the hybrid repair, the left common carotid artery was bypassed before TEVAR was performed. Although there was some concern that the aneurysm may have been mycotic, preoperative culture of aspirated fluid did not indicate active infection; thus, we performed a left upper lobectomy through a lateral thoracotomy and evacuated the thrombosed aortic sac of the previously endovascularly excluded distal aortic arch aneurysm, with subsequent aneurysmorrhaphy to cover the fully salvaged stent-graft.

Partial extraction, in which varying portions of the endograft were left in place, was performed when the endoprosthesis was adherent to the vessel wall (as is common in bifurcated abdominal endografts) or when complete removal could have unnecessarily complicated repair (eg, a stent-graft impinging on the aortic arch). Clamping the aorta with the stent-graft inside allowed us to avoid the routine use of hypothermic circulatory arrest and proceed with partial extraction. When the residual endograft was incorporated into the open repair, the replacement graft was sewn through the full thickness of the adjacent aortic wall and through the edge of the salvaged device, preferably at a point where it adhered to the aortic wall. Protruding bare-metal stents were removed with a wire cutter, and the fabric of the remaining stent-graft was included in the anastomosis to ensure hemostasis. When we completed the anastomosis and removed the clamp, the stent-graft typically reexpanded inside the aorta, allowing unobstructed blood flow inside. Of these 9 cases, aortic dissection was present in 5 . In chronic dissection cases $(\mathrm{n}=4)$, in which the prior stent-graft was deployed inside the true lumen and was separated from the aortic wall by the thick dissection flap and thrombus, we anastomosed
TABLE 2. Operative details of patients stratified by previous endovascular procedure

\begin{tabular}{|c|c|c|c|}
\hline Variable & $\begin{array}{c}\text { All } \\
(\mathrm{n}=\mathbf{6 7})\end{array}$ & $\begin{array}{c}\text { TEVAR } \\
(\mathrm{n}=45)^{*}\end{array}$ & $\begin{array}{c}\text { EVAR } \\
(\mathbf{n}=\mathbf{2 2}) \dagger\end{array}$ \\
\hline \multicolumn{4}{|l|}{ Urgency of operation } \\
\hline Elective & $39(58)$ & $25(55)$ & $14(64)$ \\
\hline Urgent & $20(30)$ & $15(33)$ & $5(23)$ \\
\hline Emergency & $8(12)$ & $5(11)$ & $3(14)$ \\
\hline \multicolumn{4}{|l|}{ Extraction of endograft } \\
\hline Partial extraction & $9(13)$ & $8(18)$ & $1(5)$ \\
\hline Complete extraction & $56(84)$ & $36(80)$ & $20(90)$ \\
\hline Full salvage & $2(3)$ & $1(2)$ & $1(5)$ \\
\hline \multicolumn{4}{|l|}{ Incision } \\
\hline Sternolaparotomy & $2(3)$ & $2(4)$ & $0(0)$ \\
\hline Thoracoabdominal & $56(84)$ & $36(80)$ & $22(100)$ \\
\hline Thoracotomy & $11(16)$ & $11(24)$ & 0 \\
\hline \multicolumn{4}{|l|}{ Extent of repair } \\
\hline Distal aortic arch (direct repair) & $1(1)$ & $1(2)$ & 0 \\
\hline Descending thoracic aorta & $12(18)$ & $12(27)$ & 0 \\
\hline $\begin{array}{l}\text { Extirpation of descending } \\
\text { thoracic aorta }\end{array}$ & $3(4)$ & $3(7)$ & 0 \\
\hline Thoracoabdominal aorta & $49(73)$ & $29(64)$ & $20(91)$ \\
\hline Extent I & $9(13)$ & $9(20)$ & 0 \\
\hline Extent II & $13(19)$ & $12(27)$ & $1(5)$ \\
\hline Extent III & $8(12)$ & $6(13)$ & $2(9)$ \\
\hline Extent IV & $19(28)$ & $2(4)$ & $17(77)$ \\
\hline Abdominal aorta, juxtarenal & $1(1)$ & 0 & $1(5)$ \\
\hline Abdominal aorta (direct repair) & $1(1)$ & 0 & $1(5)$ \\
\hline \multicolumn{4}{|l|}{ Adjuncts } \\
\hline Cerebrospinal fluid drainage & $46(69)$ & $37(82)$ & $9(41)$ \\
\hline Hypothermic circulatory arrest & $6(9)$ & $6(13)$ & 0 \\
\hline Left heart bypass & $19(28)$ & $18(40)$ & $1(5)$ \\
\hline Selective visceral perfusion & $11(16)$ & $10(22)$ & $1(5)$ \\
\hline Cold renal perfusion & $39(58)$ & $19(42)$ & $20(91)$ \\
\hline
\end{tabular}

TEVAR, Thoracic endovascular aortic repair; EVAR, endovascular aortic repair *Includes 3 bare-metal stents. $\dagger$ Includes 1 bare-metal stent. Data presented as $n$ $(\%)$ or median $[\mathrm{IQR}]$

the replacement graft at a site where we could include the full thickness of the aortic wall with the adhered stent-graft after resecting the dissecting septum and removing thrombus from the false lumen (whenever it was not patent) to allow the stent-graft to expand fully.

In 56 patients, we were able to extract the entire device, and in general, repair followed our standard approach as described earlier: graft replacement, with modifications made to manage fistula $(n=8)$ or infection without fistula $(\mathrm{n}=3)$. In cases involving fistula, EAR was first used in the native aorta as a bridge to open repair ${ }^{16}$ in 1 patient and used for complications of prior aortic repair in 3 patients. In 4 patients, fistula occurred after the primary EAR procedure. In 3 repairs with preoperative infection without fistula, the stent-graft was removed without graft replacement as part of a 2-staged repair. For 2 of these 3 repairs, a median sternotomy with upper midline laparotomy was first performed to create an extra-anatomic bypass from the ascending aorta to the abdominal aorta; this was followed by a thoracoabdominal incision for stent-graft extirpation that left behind oversewn aortic stumps. In the third extirpation repair, an axillofemoral bypass had been performed at an outside facility approximately 1 week before transfer to our facility; then, through a thoracotomy, we extirpated the infected section of the prior open repair and EAR. During repairs involving infection, we typically used an 
antibiotic-soaked replacement graft (ie, prepared tableside by soaking a polyester graft in rifampin [600 mg/vial]), and we often placed irrigation catheters to deliver antibiotics and used pedicled omentum to cover the graft; in fistula cases, additional repair of affected organs, such as lung debridement or lobectomy and esophageal or intestinal resection with subsequent primary repair, was commonly needed.

Concomitant procedures included splenectomy $(\mathrm{n}=7,10 \%)$, diaphragmatic defect or hernia repair $(n=3,4 \%)$, lobectomy $(n=2$, $3 \%)$, lung decortication $(n=1,1 \%)$, primary repair of jejunal defect $(\mathrm{n}=1,1 \%)$, repair of umbilical hernia $(\mathrm{n}=1,1 \%)$, and esophagostomy with esophageal exclusion and subsequent gastrotomy $(\mathrm{n}=1,1 \%)$.

\section{Statistical Analysis}

Statistical analyses were performed using IBM SPSS Statistics 22 (IBM Corp, Armonk, NY). Categorical variables are presented as the number and percentage. Continuous variables are presented as the median and IQR because of the non-normal distribution of the data. Overall survival and freedom from death, repair failure, or distal aortic reintervention were estimated by using the Kaplan-Meier method; information was censored at the time of hospital discharge for 1 patient who was presumed alive but lost to clinical follow-up.

\section{RESULTS \\ Early Outcomes}

In our series of 67 patients who underwent open thoracic or thoracoabdominal aortic repair after previous EAR, the operative mortality and adverse event rates were both $4 \%$ $(\mathrm{n}=3)$; all 3 patients belonged to the prior TEVAR group (Table 3). Two of the patients who died underwent operation for a pseudoaneurysm and infection of a previously placed endovascular device after complications of open repair. The third patient underwent operation for expanding thoracic aortic aneurysm. The cause of early death was sudden cardiac death of unknown cause in the first case, rupture of the homograft and multiple organ failure (MOF) in the second case, and pneumonia, sepsis, and MOF in the third case. In the overall group, there were no strokes, no persistent paraparesis or paraplegia, and 1 case $(1 \%)$ of persistent renal failure necessitating hemodialysis.

\section{Late Outcomes}

The estimated postoperative survivals at 1,3 , and 5 years were $85 \% \pm 4 \%, 74 \% \pm 6 \%$, and $60 \% \pm 8 \%$, respectively (median follow-up, 35.8 months; IQR, 16.7-52.4 months) (Figure 2). In total, there were 19 $(28 \%)$ late deaths, 5 of which occurred in patients who had undergone operation with infection. Late mortality was $33 \%(n=15)$ in the TEVAR group and $18 \%(n=4)$ in the EVAR group. The cause of late death could not be confirmed for 6 patients. The cause of death for the 13 remaining patients was aneurysm rupture $(\mathrm{n}=3)$, end-stage neoplastic disease $(\mathrm{n}=2)$, cardiac complications $(n=4)$, and repair failure $(n=4$ : persistent infection and sepsis $[\mathrm{n}=1]$, recurrence of fistula $[\mathrm{n}=1]$, and newly formed fistula $[\mathrm{n}=2])$. Profuse hemoptysis contributed to the deaths of 2 patients; it stemmed from a recurrent
TABLE 3. Early outcomes of patients stratified by previous endovascular procedure

\begin{tabular}{|c|c|c|c|}
\hline Variable & $\begin{array}{c}\text { All } \\
(\mathbf{n}=67)\end{array}$ & $\begin{array}{c}\text { TEVAR } \\
(n=45)^{*}\end{array}$ & $\begin{array}{c}\text { EVAR } \\
(\mathbf{n}=\mathbf{2 2}) \dagger\end{array}$ \\
\hline Adverse event $\ddagger$ & $3(4)$ & $3(7)$ & 0 \\
\hline Operative death $\S$ & $3(4)$ & $3(7)$ & 0 \\
\hline In-hospital & $3(4)$ & $3(7)$ & 0 \\
\hline $30-d$ & $1(1)$ & $1(2)$ & 0 \\
\hline Stroke & 0 & 0 & 0 \\
\hline Persistent SCD $\|$ & 0 & 0 & 0 \\
\hline Temporary paraplegia & $2(3)$ & $1(2)$ & $1(5)$ \\
\hline Temporary paraparesis & $2(3)$ & $2(4)$ & 0 \\
\hline Respiratory failure & $11(16)$ & $10(22)$ & $1(5)$ \\
\hline $\begin{array}{l}\text { Necessitating } \\
\text { tracheostomy }\end{array}$ & $9(13)$ & $9(20)$ & 0 \\
\hline Acute renal dysfunction & $4(6)$ & $2(4)$ & $2(9)$ \\
\hline $\begin{array}{l}\text { Renal failure necessitating } \\
\text { dialysis }\end{array}$ & $3(4)$ & $2(4)$ & $1(5)$ \\
\hline Persistent $\|$ & $1(1)$ & $1(2)$ & 0 \\
\hline Temporary & $2(3)$ & $1(2)$ & $1(4.5)$ \\
\hline Cardiac complication & $7(10)$ & $6(13)$ & $1(5)$ \\
\hline $\begin{array}{l}\text { Left vocal cord } \\
\text { paralysis }\end{array}$ & $18(27)$ & $18(40)$ & 0 \\
\hline $\begin{array}{l}\text { Early survivors: } \\
\text { length of ICU } \\
\text { stay, d }\end{array}$ & $4.0[3.0-6.5]$ & $4.0[3.0-10.0]$ & $3.0[2.0-4.8]$ \\
\hline
\end{tabular}

Early survivors: $10.0[8.0-13.5] 11.0[9.0-16.0] 8.0[7.0-11.0]$

length of

hospital stay,

overall, $\mathrm{d}$

$T E V A R$, Thoracic endovascular aortic repair; $E V A R$, endovascular aortic repair; $S C D$, spinal cord deficit (ie, paraplegia or paraparesis); $I C U$, intensive care unit. *Includes 3 bare-metal stents. †Includes 1 bare-metal stent. $\ddagger$ Defined as operative death or persistent (present at hospital discharge) stroke, paraplegia, paraparesis, or renal failure necessitating dialysis. §Operative (or early) death was defined as any death taking place within 30 days of the operation or before final discharge from our or any hospital or long-term acute care facility. $\|$ Present at the time of hospital discharge or early death. Data presented as n (\%) or median [IQR].

aortobronchial fistula in 1 and a newly developed aortobronchial fistula in the other.

Distal aortic reintervention because of repair failure or progression of aortic disease was necessary after 7 repairs; 1 patient had reintervention for both repair failure and progression of aortic disease. Regarding repair failure, we had 1 early repair failure, which involved the use of an aortic homograft as described earlier. In addition, we had 3 late repair failures necessitating further repair, and 2 late repair failures contributing to death. In a patient without infection, a pseudoaneurysm developed shortly after open repair. Although it was successfully treated with EAR, during reintervention the visceral patch anastomosis was disrupted, and open correction was then needed. This 


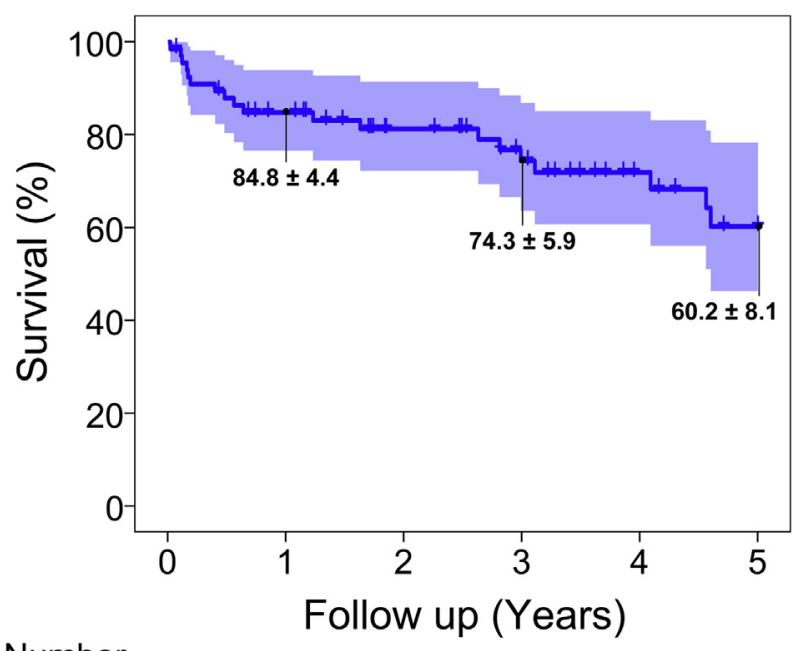

Number

$\begin{array}{lllllll}\text { at Risk } & 67 & 52 & 40 & 31 & 20 & 14\end{array}$

FIGURE 2. Kaplan-Meier curve showing late survival estimates for 67 patients after open repair for complications of previous EAR. Confidence intervals are indicated by the shaded bands.

patient remains alive 8 years after repair. Another patient with an aortobronchopulmonary fistula at the time of repair developed recurrent graft infection, which necessitated additional open repair; after a lengthy course of treatment, this patient died 6.5 months after operation. A patient without infection had additional reintervention 5 months later for progressive aortic disease (EVAR to treat worsening abdominal aortic disease and a left iliac aneurysm); after an additional 2 months, an open thoracoabdominal exploration was needed to repair a para-anastomotic chylous/lymphocele sac, which was opened, drained, and covered by a pedicled omental flap. This patient died 5.5 years later. Regarding the progression of aortic disease, further repair was necessary in 4 cases (3 additional open thoracoabdominal aortic aneurysm repairs and 1 additional EVAR). Rates for freedom from death, repair failure, or distal aortic reintervention at 1,3 , and 5 years were estimated to be $82 \% \pm 5 \%, 69 \% \pm 6 \%$, and $49 \% \pm 9 \%$, respectively (Figure 3).

\section{DISCUSSION}

EAR for diseases of both the thoracic and the abdominal aorta has revolutionized the field and has been applied with various degrees of success. Although initially used only in significantly compromised patients for whom open repair would carry prohibitively high risk, EAR has been extended to patients with fewer comorbidities because of its minimal invasiveness, ease of application, and lower associated perioperative morbidity and mortality. ${ }^{1,2,17}$ However, the long-term durability of EAR is largely unknown, and its expanding use-both in challenging clinical situations and in general-has increased the rate of EAR-related complications, suboptimal outcomes, and procedural

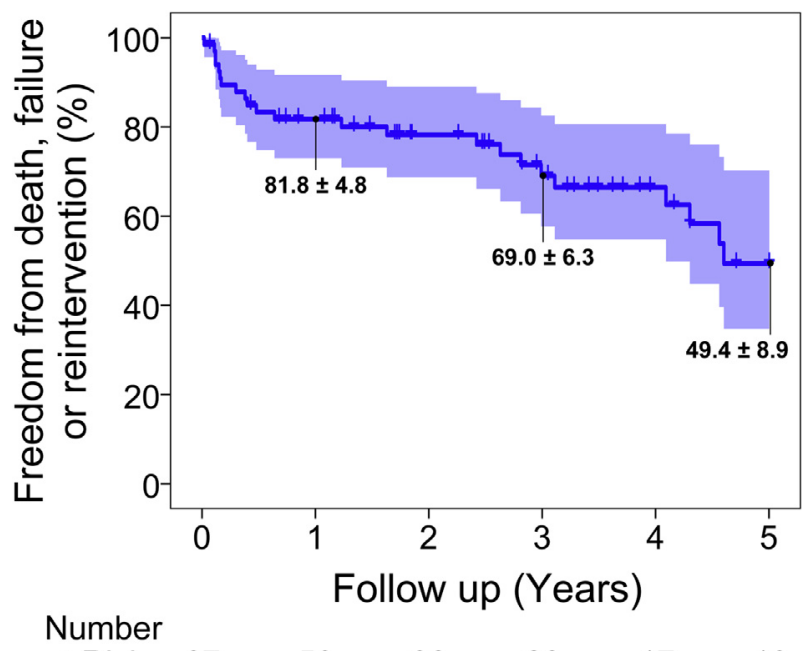

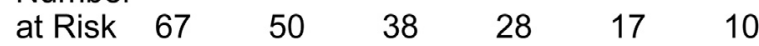

FIGURE 3. Kaplan-Meier curve showing freedom from death, repair failure, or distal aortic reintervention (ie, additional open or endovascular repair of the descending thoracic, thoracoabdominal, or abdominal aorta because of repair failure or progression of aortic disease) for 67 patients after open repair for complications of previous EAR. Confidence intervals are indicated by the shaded bands.

failures. We present our experience over the last 19 years with the open repair of severe EAR complications in 67 patients. Our findings indicate a steady increase in the number of these challenging procedures over time (Figure 1). However, we found that our early outcomes are acceptable, especially in patients without infection, coinciding with reports from other experienced centers. ${ }^{18-22}$

Expanding the use of endovascular techniques with existing endovascular devices (which were designed for the distal aorta) to include other areas of the aorta (eg, the aortic arch) may involve suboptimal proximal or distal landing zones and can lead to complications, including type Ia or Ib endoleaks and expanding aortic aneurysms. ${ }^{23}$ Moreover, inherent inadequacies of EAR can lead to failures, such as endoleak types II, III, and IV, all of which involve continuous filling and expansion or even rupture of the aneurysmal sac after the endovascular device is implanted. Endoleak was a common indication for subsequent open repair in our patients, as seen in approximately half $(45 \%)$ of them.

Moreover, the role of EAR in the management of chronic aortic dissection with aneurysmal dilatation has been the subject of continuing controversy in the literature. . $^{3,6,8,9}$ The main concern about this approach is that the rigidity of the chronically dissected and thickened septum makes it difficult to remodel the false lumen. In addition, complications can arise from ongoing perfusion of the false lumen in the aortic segment treated with EAR, due to retrograde perfusion from downstream segments without EAR or the presence of multiple septal fenestrations. However, it is possible that these 
complications could be avoided in patients who have very focal aortic dilatations with no septal fenestrations in their vicinity. Our finding that $33 \%(\mathrm{n}=22)$ of the patients in this series had chronic aortic dissection at the time of EAR could imply that its use is occasionally futile.

Open repair after EAR was complicated by infection in 11 patients, including 8 with fistula; infection appeared to be present at the time of EAR in 7 patients and after EAR in 4 patients. Our strategies for treating these highly challenging cases of infection included removing the entire device and, whenever possible, replacing it with a rifampin-soaked prosthetic graft (Video 1). In 1 patient in whom EAR was performed to treat an infected aortic graft concomitant with a pseudoaneurysm, we replaced the affected aortic section with a homograft. However, we abandoned this strategy after the homograft repeatedly ruptured, despite 2 open repairs of the homograft defect and 1 further endovascular repair; ultimately, this patient died. Consequently, we do not use homografts to replace the affected aortic section of the descending or thoracoabdominal aorta because of concerns about their poor durability in this location. In cases of difficult-tomanage infection, extirpating the affected segment of the aorta may be necessary. In another case of an infected aortic graft, pseudoaneurysm, and fistula, EAR was performed, along with extra-anatomic bypass, at an outside center; in our repair, we completely extirpated the affected section, but ultimately this patient died. The other 2 patients with extirpation survived 5.5 and 6.5 months.

Antibiotic therapy should be directed by results of the culture of the infected material. In addition to the requisite

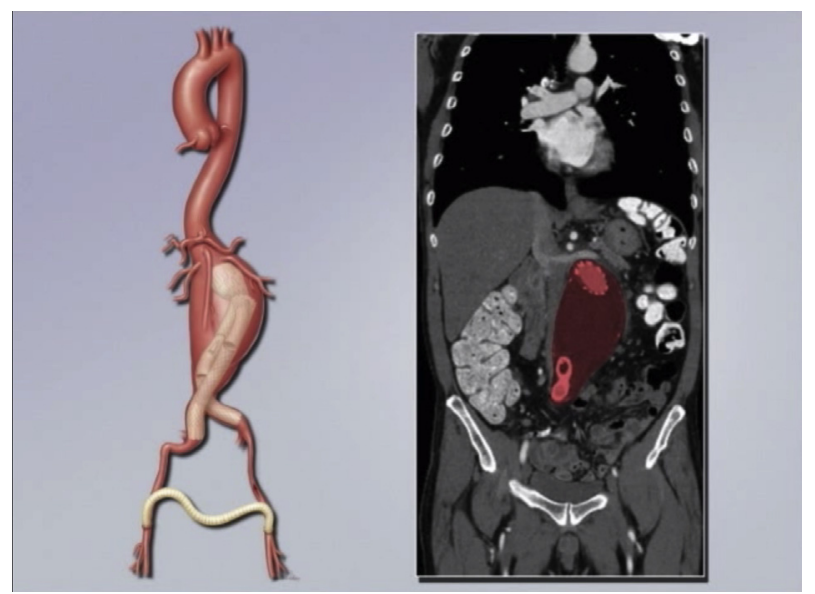

VIDEO 1. Removal of an infected aortic stent-graft and in situ thoracoabdominal aortic reconstruction in a 65-year-old man. This patient underwent extent IV thoracoabdominal aortic aneurysm repair and had an unremarkable recovery. He remains well and without the need for further aortic intervention more than 7 years after the operation. Used with the permission of Baylor College of Medicine. Video available at: http://www.jtcvsonline.org/article/S0022-5223(17)31783-X/fulltext.
TABLE 4. Outcomes of patients with preoperative infection

\begin{tabular}{lc}
\hline \multicolumn{1}{c}{ Variable } & All $(\mathbf{n}=\mathbf{1 1})$ \\
\hline Adverse event* & $2(18)$ \\
Operative death & $2(18)$ \\
$\quad$ In-hospital & $2(18)$ \\
30-d & 0 \\
Persistent stroke $\dagger$ & 0 \\
Persistent spinal cord deficit ${ }^{\dagger}$ & 0 \\
Persistent renal failure necessitating dialysis $\dagger$ & $1(9)$ \\
Cardiac complication & $5(46)$ \\
\hline Late death & $5(46)$ \\
\hline
\end{tabular}

*Defined as operative death or persistent (present at hospital discharge) stroke, paraplegia, paraparesis, or renal failure necessitating dialysis. $\nmid$ Present at the time of hospital discharge or early death. Data presented as n (\%).

full postoperative course of intravenous antibiotics, we advocate the use of lifelong, suppressive, oral antibiotic therapy. ${ }^{13}$ Despite these efforts, patients with infection had the worst short- and long-term prognoses in our study group, with $64 \%$ overall mortality ( 2 early and 5 late deaths) (Table 4). Our findings concur with those of other groups for infected stent-grafts ${ }^{21,22}$ and aortic fistulation after EAR. ${ }^{18-20,24}$ Recurrence or persistence of the infection and subsequent MOF due to septic shock is the usual pattern of treatment failure and ultimate demise of these patients. A high level of alertness should be maintained for patients who receive EAR who present with clinically suspected infection and computed tomography evidence of infection (eg, perigraft gas bubbles, fistula); aggressive management as described should be implemented in these patients.

The use of EAR in patients with connective tissue disorder (CTD) is considered off-label ${ }^{25-29}$ because of the inherently defective aortic tissue, which may lead to the continuous expansion of the aortic aneurysmal wall and the loss of effective sealing of the stent-graft to the landing zones, leading ultimately to expanding aneurysms and dissections and EAR failure. ${ }^{30}$ However, EAR can be useful in patients with CTD when the stent-graft can be landed inside sections of a previously placed aortic graft, as when treating pseudoaneurysms or patch aneurysms after previous open repair or in secondary EAR of progressive aneurysmal disease. ${ }^{31,32}$ Our group included a total of 17 patients $(25 \%)$ who presented with CTD (Marfan and Loeys-Dietz syndromes), implying that genetically triggered aortic disorders play an important role in serious complications after EAR requiring open repair. Furthermore, all 17 patients with CTD also had distal aortic dissection, which can cause progressive expansion of the false lumen through continued retrograde perfusion.

Device collapse 18,20,33,34 $^{\text {and } \text { migration }^{35}}$ can pose significant danger to patients and necessitate immediate intervention to prevent catastrophic consequences. 
However, we encountered only 1 case with migration (an abdominal cuff endograft) and found no device collapse. Furthermore, the follow-up data we have collected to date do not suggest that partial extraction can lead to such catastrophic events as device component separation, collapse, or rupture.

\section{Study Limitations}

Limitations of our study include its retrospective design and inherent selection bias related to referral patterns and self-selection of patients who present to our tertiary clinic for repair; consequently, our experience may not be generalizable to other centers. Also, because most EARs were performed at an outside institution, we could not analyze detailed data regarding EAR or examine the true incidence of serious post-EAR complications that require open thoracic or thoracoabdominal repair, nor could we identify predictors of such complications. In addition, the number of patients was not sufficient to provide statistical power for comparing outcomes between those with previous TEVAR and those with previous EVAR.

\section{CONCLUSIONS}

The use of EAR for an expanding variety of aortic diseases is associated with subsequent complications that may necessitate open repair through a thoracic approach. At an experienced center, ${ }^{18-22}$ early outcomes after open repair can be acceptable, except for patients with infection. In many patients, the need for open repair arises more than 1 year after their previous EAR; thus, vigilant postoperative surveillance after EAR procedures is desirable, especially in cases involving suboptimal landing zones, chronic aortic dissection, and known endoleak, and in patients with CTD. Patients who develop complications after EAR may represent a subset of patients who remain at risk of future aortic events even after open, corrective repair; such patients need better and lifelong postoperative imaging surveillance.

\section{Conflict of Interest Statement}

O.P. has served as a consultant for Medtronic, Inc, and WL Gore \& Associates. S.A.L. has served as a consultant for Medtronic, Inc, and Vascutek Terumo; has served as an Advisory Board Member for Baxter Healthcare; has served as a principal investigator for clinical studies sponsored by Vascutek Terumo and Baxter Healthcare; and has served as a co-investigator for clinical studies sponsored by Medtronic, Inc, WL Gore \& Associates, GlaxoSmithKline, Cook, Inc, and Cytosorbants, Inc. J.S.C. participates in clinical research trials conducted by GlaxoSmithKline, Edwards Lifesciences, and Bolton Medical; consults for, receives royalties and a departmental educational grant from, and participates in clinical trials for Vascutek Terumo; and consults and participates in clinical trials for
Medtronic, Inc, and WL Gore \& Associates. All other authors have nothing to disclose with regard to commercial support.

The authors thank Laurie Fondren for managing subject enrollment; Scott A. Weldon, MA, CMI, for creating the illustrations and producing the video; and Rebecca A. Bartow, $\mathrm{PhD}$, for providing editorial support.

\section{References}

1. Hughes K, Guerrier J, Obirieze A, Ngwang D, Rose D, Tran D, et al. Open versus endovascular repair of thoracic aortic aneurysms: a Nationwide Inpatient Sample study. Vasc Endovascular Surg. 2014;48:383-7.

2. Scali ST, Goodney PP, Walsh DB, Travis LL, Nolan BW, Goodman DC, et al. National trends and regional variation of open and endovascular repair of thoracic and thoracoabdominal aneurysms in contemporary practice. $J$ Vasc Surg. 2011;53:1499-505.

3. Andersen ND, Keenan JE, Ganapathi AM, Gaca JG, McCann RL, Hughes GC. Current management and outcome of chronic type B aortic dissection: results with open and endovascular repair since the advent of thoracic endografting. Ann Cardiothorac Surg. 2014;3:264-74.

4. Faure EM, Canaud L, Agostini C, Shaub R, Boge G, Marty-ané C, et al. Reintervention after thoracic endovascular aortic repair of complicated aortic dissection. J Vasc Surg. 2014;59:327-33.

5. Hanna JM, Andersen ND, Ganapathi AM, McCann RL, Hughes GC. Five-year results for endovascular repair of acute complicated type B aortic dissection. J Vasc Surg. 2014;59:96-106.

6. Hughes GC, Ganapathi AM, Keenan JE, Englum BR, Hanna JM, Schechter MA, et al. Thoracic endovascular aortic repair for chronic DeBakey IIIb aortic dissection. Ann Thorac Surg. 2014;98:2092-8.

7. Nozdrzykowski M, Luehr M, Garbade J, Schmidt A, Leontyev S, Misfeld M, et al. Outcomes of secondary procedures after primary thoracic endovascular aortic repair. Eur J Cardiothorac Surg. 2016;49:770-7.

8. Patterson B, Holt P, Nienaber C, Cambria R, Fairman R, Thompson M. Aortic pathology determines midterm outcome after endovascular repair of the thoracic aorta: report from the Medtronic Thoracic Endovascular Registry (MOTHER) database. Circulation. 2013;127:24-32.

9. Scali ST, Beck AW, Butler K, Feezor RJ, Martin TD, Hess PJ, et al. Pathologyspecific secondary aortic interventions after thoracic endovascular aortic repair. J Vasc Surg. 2014;59:599-607.

10. LeMaire SA, Price MD, Green SY, Zarda S, Coselli JS. Results of open thoracoabdominal aortic aneurysm repair. Ann Cardiothorac Surg. 2012; $1: 286-92$.

11. Wong DR, Parenti JL, Green SY, Chowdhary V, Liao JM, Zarda S, et al Open repair of thoracoabdominal aortic aneurysm in the modern surgical era: contemporary outcomes in 509 patients. J Am Coll Surg. 2011;212:569-81.

12. LeMaire SA, Miller CC III, Conklin LD, Schmittling ZC, Koksoy C, Coselli JS A new predictive model for adverse outcomes after elective thoracoabdominal aortic aneurysm repair. Ann Thorac Surg. 2001;71:1233-8.

13. Coselli JS, Green SY, LeMaire SA. When stent-grafts fail: extraction and open surgical repair of the thoracic aorta. Tex Heart Inst J. 2011;38:658-60.

14. Coselli JS, Kim I, Preventza O, LeMaire SA, Weldon SA. Extent II thoracoabdominal aortic aneurysm repair: how I do it. Semin Thorac Cardiovasc Surg. 2016;28:221-37.

15. Coselli JS, Spiliotopoulos K, Preventza O, de la Cruz KI, Amarasekara H, Green SY. Open aortic surgery after thoracic endovascular aortic repair. Gen Thorac Cardiovasc Surg. 2016;64:441-9.

16. Matos JM, de la Cruz KI, Ouzounian M, Preventza O, LeMaire SA, Coselli JS Endovascular repair as a bridge to surgical repair of an aortobronchial fistula complicating chronic residual aortic dissection. Tex Heart Inst J. 2014;41:198-202.

17. Makaroun MS, Dillavou ED, Kee ST, Sicard G, Chaikof E, Bavaria J, et al. Endovascular treatment of thoracic aortic aneurysms: results of the phase II multicenter trial of the GORE TAG thoracic endoprosthesis. J Vasc Surg. 2005;41:1-9.

18. Canaud L, Alric P, Gandet T, Ozdemir BA, Albat B, Marty-Ane C. Open surgical secondary procedures after thoracic endovascular aortic repair. Eur J Vasc Endovasc Surg. 2013;46:667-74.

19. Girdauskas E, Falk V, Kuntze T, Borger MA, Schmidt A, Scheinert D, et al Secondary surgical procedures after endovascular stent grafting of the thoracic 
aorta: successful approaches to a challenging clinical problem. J Thorac Cardiovasc Surg. 2008;136:1289-94.

20. Miyahara S, Nomura Y, Shirasaka T, Taketoshi H, Yamanaka K, Omura A, et al. Early and midterm outcomes of open surgical correction after thoracic endovascular aortic repair. Ann Thorac Surg. 2013;95:1584-90.

21. Roselli EE, Abdel-Halim M, Johnston DR, Soltesz EG, Greenberg RK, Svensson LG, et al. Open aortic repair after prior thoracic endovascular aortic repair. Ann Thorac Surg. 2014;97:750-6.

22. Szeto WY, Desai ND, Moeller P, Moser GW, Woo EY, Fairman RM, et al. Reintervention for endograft failures after thoracic endovascular aortic repair. J Thorac Cardiovasc Surg. 2013;145:S165-70.

23. LeMaire SA, Green SY, Kim JH, Sameri A, Parenti JL, Lin PH, et al. Thoracic or thoracoabdominal approaches to endovascular device removal and open aortic repair. Ann Thorac Surg. 2012;93:726-33.

24. Dumfarth J, Dejaco H, Krapf C, Schachner T, Wykypiel H, Schmid T, et al. Aorto-esophageal fistula after thoracic endovascular aortic repair: successful open treatment. Aorta (Stamford). 2014;2:37-40.

25. Botta L, Russo V, La Palombara C, Rosati M, Di Bartolomeo R, Fattori R. Stent graft repair of descending aortic dissection in patients with Marfan syndrome: an effective alternative to open reoperation? J Thorac Cardiovasc Surg. 2009;138: 1108-14.

26. Pacini D, Parolari A, Berretta P, Di Bartolomeo R, Alamanni F, Bavaria J. Endovascular treatment for type B dissection in Marfan syndrome: is it worthwhile? Ann Thorac Surg. 2013;95:737-49.

27. Takahashi Y, Tsutsumi Y, Shirakawa Y, Ohashi H. Total aortic repair in Marfan syndrome using stent grafting with hybrid techniques. J Vasc Surg. 2010;52:1365-6.

28. Waterman AL, Feezor RJ, Lee WA, Hess PJ, Beaver TM, Martin TD, et al. Endovascular treatment of acute and chronic aortic pathology in patients with Marfan syndrome. J Vasc Surg. 2012;55:1234-41.
29. Ehrlich MP, Nienaber CA, Rousseau H, Beregi JP, Piquet P, Schepens M, et al. Short-term conversion to open surgery after endovascular stent-grafting of the thoracic aorta: the Talent thoracic registry. J Thorac Cardiovasc Surg. 2008; 135:1322-6.

30. Preventza O, Mohammed S, Cheong BY, Gonzalez L, Ouzounian M, Livesay JJ, et al. Endovascular therapy in patients with genetically triggered thoracic aortic disease: applications and short- and mid-term outcomes. Eur J Cardiothorac Surg. 2014;46:248-53.

31. Roselli EE, Idrees JJ, Lowry AM, Masabni K, Soltesz EG, Johnston DR, et al. Beyond the aortic root: staged open and endovascular repair of arch and descending aorta in patients with connective tissue disorders. Ann Thorac Surg. 2016;101:906-12.

32. Schwill S, LeMaire SA, Green SY, Bakaeen FG, Coselli JS. Endovascular repair of thoracic aortic pseudoaneurysms and patch aneurysms. J Vasc Surg. 2010;52: 1034-7.

33. Geisbusch P, Hoffmann S, Kotelis D, Able T, Hyhlik-Durr A, Bockler D. Reinterventions during midterm follow-up after endovascular treatment of thoracic aortic disease. J Vasc Surg. 2011;53:1528-33.

34. Tadros RO, Lipsitz EC, Chaer RA, Faries PL, Marin ML, Cho JS. A multicenter experience of the management of collapsed thoracic endografts. J Vasc Surg. 2011;53:1217-22.

35. Langer S, Mommertz G, Koeppel TA, Schurink GW, Autschbach R, Jacobs MJ. Surgical correction of failed thoracic endovascular aortic repair. J Vasc Surg. 2008;47:1195-202.

Key Words: neurysm (aorta), aortic dissection, aortic operation, reoperation, thoracoabdominal, descending thoracic, endovascular aortic repair 